\title{
VOLUNTARY RISK TAKING BY YOUNG BICYCLISTS: A CASE STUDY OF UNIVERSITY STUDENTS AT MONTREAL
}

\author{
Shohel Reza Amin \\ Highways \& Transportation Engineering, Faculty of Engineering, Environment \& Computing, \\ Coventry University, Priory St, Sir John Laing Building, Room No. JL132, Coventry, \\ West Midlands CV1 5FB, United Kingdom \\ E-mails: shohel.amin@coventry.ac.uk
}

\begin{abstract}
Young bicyclists in Montreal are taking voluntary risks such as bicycling without wearing helmet and braking system of bicycle although they are aware of the presence of danger. This article analyses the behaviour of young bicyclists taking voluntary risks. The university students in Montreal are considered as the case study since they are more risk takers and the bicycle is a favorite mode of transport among them. This study reveals that half of the respondents did not use helmets. They were also spontaneously taking a risk by high speeding, violating signals, bicycling in mixed traffic, ignoring protective equipment after dark, and avoiding the bicycle designated roads. They were taking voluntary risks based on their attitude, subjective norm and perceived behavioural control. They did not perceive the severity of risks since they experienced prelevant and unremarkable minor injuries. The attractiveness of risk and accomplishing the risk activities encouraged the young bicyclists to take voluntary risks repeatedly. Increasing feelings of vulnerability among young bicyclists reduce voluntary risks taking attitude and physical and psychological sufferings of the victims of bicycle-related accidents. Findings of this study suggest that the City of Montreal as well as other cities consider the behaviour of bicyclists particularly the young people to avoid bicycle-related accidents along with other physical measures.
\end{abstract}

Keywords: behaviour, helmet, information, law, perception, risk.

\section{Introduction}

City of Montreal and Quebec government in Canada have taken measures to ensure the safety of bicyclists such as the expansion of bicycle-designated roads, the increment of bicycle parking spaces and sponsor a bicycle sharing rental program known as BIXI. The city of Montreal adopts a revised 2008 Transportation Plan for its bicycle designated roads; and plans for increasing the designated and shared roadways to 1280 kilometres from the current 600 kilometres during the next 12 to 15 years. In spring 2014, Transport Minister of Quebec provincial government mandated a working group to recommend on sharing the road signs by bicyclists, pedestrians, and motorists. However, bicycle-related accidents are still at a significant level in Montreal regardless of the initiatives taken by the municipal and provincial governments. Several provinces of Canada have enacted helmet laws, but the City of Montreal is reluctant to use helmets obligatory defining it as a repressive approach. The City of Montreal recommends all bicyclists to wear a helmet, while bicycling. Young bicyclists in Montreal are taking voluntary risks such as bicycling without wearing helmet and braking system of bicycle although they are aware of the presence of danger, which if not adequately circumvented resulting in injuries and death.

This article analyses the behaviour of young bicyclists taking the voluntary risk. The university students in Montreal are considered as the case study since they are more risk takers and the bicycle is a favorite mode of transport among them. Initially, this article discusses the current context of bicycle-related accidents and injuries in Montreal to understand the pattern of bicycle-related accidents. Literature review explains the arguments of several studies for and against the helmet use and helmet law to reduce bicycle-related accidents and injuries. A questionnaire survey in the form of cohort group discussion was conducted among university students to understand their behaviour towards taking voluntary risks.

\section{Bicyclists and road accidents}

There is an increasing trend of bicycling without a braking system of bicycles and wearing helmet among young 
Montrealers resulting in significant injuries and fatalities. For instance, a young bicyclist was run over and killed by a truck near the Lachine Canal of Montreal, while riding a bicycle without the braking system. A young bicyclist did not wear a helmet and suffered serious head injuries after falling from his bicycle, while riding along St. Antoine Street in Montreal. A doctor brushed by a passing car and had minor injuries, while riding a bicycle and turning left from Décarie Boulevard onto de Maisonneuve Boulevard near the McGill University Health Centre (MUHC) super hospital, a manoeuvre that is prohibited by the City of Montreal at that intersection.

Bicycling gains popularity in Montreal and bicycle-related accidents are increasing simultaneously. Montreal has experienced the highest and second highest bicycle-related accidents in Quebec province and Canada, respectively. From 1999 to 2003, an average of 950 bicyclists was injured every year in Montreal (Strauss et al. 2013). Less than 50\% of bicyclists are voluntarily taking the risk without wearing a helmet, while bicycling in Montreal (Ji et al. 2006). This behaviour of bicyling without wearing a helmet increases the potential risks of significant injuries particularly head and brain injuries. The Trauma Centre of Montreal General Hospital reports that more than $50 \%$ of injured bicyclists were not wearing a helmet during accidents in 2012-2014. Downtown Montreal Trauma Centre admitted 71 injured bicyclists with an average Injury Severity Score (ISS) of 16 in the year 2011 (Ji et al. 2006). Forty percent of these injured bicyclists sustained a traumatic brain injury (TBI) (average ISS: 24). Among these patients with TBI, $79 \%$ were not wearing a helmet at the time of their injuries (Ji et al. 2006). Costa (2014) estimated that $75 \%$ of patients with TBI admitted to McGill University Health Centre, Montreal General Hospital (MGH) and a tertiary trauma centre following bicycle-related accidents were not wearing a helmet during 2007-2011. Statistics on injured bicyclists admitted to Canadian emergency departments (EDs) revealed that head injuries ranked the most severe injuries $(20 \%-40 \%)$ and half of the bicyclists with head injuries were youth (Hagel, Yanchar 2013). McIntosh et al. (2013) experimented that the unprotected bicyclist would suffer at least Concussion/ Mild Traumatic Brain Injury and Persistent (concussion/ mTBI) symptoms in the least severe impact and had a more than $30 \%$ chance of suffering a severe skull or brain injury with impacts of greater severity. The severe skull and brain injury risk for the bicyclist without wearing a helmet increases with increasing head impact severity.

Several provinces in Canada enacted helmet law predominantly for young bicyclists and have experienced the proportion of helmet use to $48 \%-66 \%$ for all ages (Ji et al. 2006). These statistics advocate that helmet law increase the use of a helmet. However, there is a substantial debate among the transportation research communities about the effectiveness of helmet law on helmet use. Similar other studies (Karkhaneh et al. 2006; Macpherson, Spinks 2008; Macpherson et al. 2006; Jewett et al. 2016) studied that helmet law increased helmet use, particularly among young bicyclists. The highest increase in helmet use in
Canada was observed in Alberta province that was $72 \%-$ $95 \%$ among children younger than 13 years of age after the introduction of a helmet law for bicyclists younger than 18 years old (Karkhaneh et al. 2011).

On the contrary, a group of researchers (Fyhri et al. 2012; Kett et al. 2016; Robinson 2006; Turner et al.2011) are against the helmet law and argued that introduction of helmet law discouraged bicyclists and left the riskiest bicyclists on roads. Robinson (2006) claimed that bicyclists were more risk taker and aggressive, while wearing a helmet. Walker (2007) observed that car drivers had more tendency to overtake cyclists with fewer safety margins when the cyclists put on helmets. Kett et al. (2016) find no any significant change in the proportion of bicyclists admitted to the hospital and treated for head injuries in Seattle and King County after enacting all-ages bicycle helmet law in 2003.

Since helmet law is a debatable issue and is referred to repression, the City of Montreal has focused on extending bicycle-designated roads to reduce bicycle-related accidents. However, records show that a significant proportion of bicycle-related accidents were on the bicycle designated roads and intersections in Montreal (Fig. 1). For example, Christophe-Colomb and Crémazie, Berri and Ontario, Rachel and Saint-Denis, Christophe-Colomb and Jarry, Gilberte-Dubé and Wellington, Fort and du Maisonneuve, Berri and Viger, Papineau and Sherbrooke, Mont-Royal and Papineau, and Papineau and Rachel intersections experienced highest bicycle-related accidents during 2006-2011. The intersections of Dickson and Notre-Dame, Henri-Bourassa and Papineau, Iberville and Saint Joseph, Garon and Henri-Bourassa, Henri-Bourassa and Marcel-Laurin, Notre-Dame and Pie-IX, Crémazie and Saint-Laurentinter Nord-Est, René-Lévesque and Sanguinet, Molson and Saint Joseph, and Pont Jacques-Cartier are the highly dangerous locations for bicyclists during 2006-2011. A high number of bicyclerelated accidents occurred at the bicycle-designated roads and intersections because of the high volume of bicycle traffic, risk taking attitude and disobedience of traffic signals.

Bicycle-related accidents and injuries cannot be prevented merely by enacting helmet law and constructing bicycle- designated roads. Several factors guide and influence

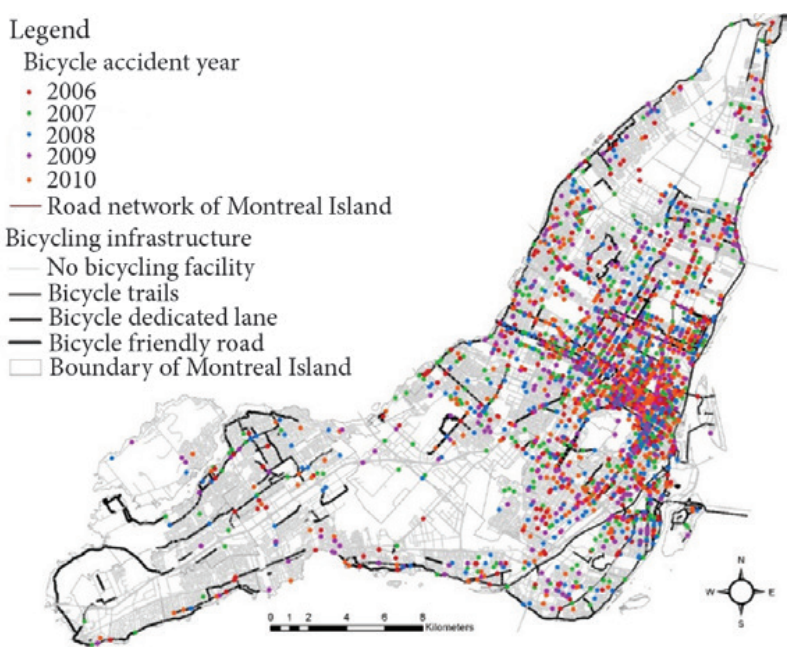

Fig. 1. Bicycle path and bicycle-related accidents from 2006 to 2010 
the young bicyclists to take a risk such as willingness, perception, behaviour, and anticipation. This study analyses the behaviour of young bicyclists taking voluntary risks.

\section{Methodology}

A questionnaire survey was conducted in the form of cohort group discussion among randomly selected 200 university students at Montreal during February-April 2015. Data on bicyclist's injuries were collected from the Trauma Centre of Montreal General Hospital from 2012 to 2014. Among the respondents, $62 \%$ and $34 \%$ were male and female, respectively. Three-fifth respondents were occasional bicyclists, while two-fifth were regular. Most of the respondents (73\%) were bicycling for recreational and exercise purposes, while $23 \%$ were for work and educational purposes and 3\% were for shopping and groceries. Most of the respondents had bicycling experiences for years, for example, $39 \%$ and $44 \%$ respondents had more than four and five years of bicycling experiences, respectively.

\section{Discussion}

Discussion with respondents reveals tha ${ }^{\mathrm{t}}$ more than half of them were not wearing a helmet, while bicycling. Among these respondents, $38 \%$ did not wear a a helmet for short trips, $29 \%$ never bought a helmet, $29 \%$ felt uncomfortable wearing helmet, $4 \%$ believed that helmet was expensive, and $4 \%$ felt that helmet obstructed their vision, while bicycling. The decision not to wear helmet depended on the attitude, subjective norm and perceived behavioural control of the bicyclists that persuade them to take the risk (Bamberg et al. 2003; Lajunen 2016). Attitude is a combination of beliefs about the behaviour and consequences (Bamberg et al. 2003). For example, bicyclists belief that Montreal is a bicycle friendly city or they are safe bicycling on a designated road, or bicycle-related injuries are minor. Subjective norm develops from normative beliefs and motivation to comply (Bamberg et al. 2003). The strict laws and considerable penalty fees restrict the vehicle drivers to take the voluntary risk. Since there is no helmet law and bicyclists are privileged road users in Montreal, a significant number of bicyclists are taking the voluntary risk of not wearing a helmet, while bicycling and frequently disobeying traffic signals. Perceived behavioural control is based on beliefs that facilitate or constrain the performance of a particular behaviour (Bamberg et al. 2003). University students are less likely to wear helmet and restraint themselves from over speeding, violating signals or taking the risk, while bicycling. The theory of planned behaviour (TPB) states that these factors are considered separately before taking any decision. However, a young bicyclist takes a decision automatically without conscious intent or think (Bamberg et al. 2003).

Respondents (38\%) who did not wear a helmet for short trips voluntarily took the risk assuming either there was less risk for short trips or they were not motivated enough to wear helmet buying a snack from a nearby grocery store. This decision making process is defined by the prospect theory that is a descriptive model of choice initially developed by Kahneman and Tversky (1979) for formulating decisions involving risk. The young bicyclists preferred not to wear a helmet for short trips because they did not anticipate any loss assuming the utility of gains as zero. This understanding seems invalid based on the findings of this study. This study identifies that a significant proportion of bicycle-related accidents occurred at short trips. For example, $65 \%$ respondents said that they had accidents on the local access roads.

Young bicyclists take risk hypothesizing that the purchase of helmet is not a worthy alternative as the possibility of an accident, the severity of the injury and associated costs are not so substantial. Inappropriately, respondents underestimated the direct and indirect gains of wearing a helmet and confused with its monetary value. Previous studies applied the cost-benefit analyses to advocate the helmet law or wearing a helmet as a financially unprofitable initiative (Hendrie et al. 1999; Robinson 2007; Sieg 2016; Taylor, Scuffham 2002). Taylor and Scuffham (2002) estimated that the purchasing cost of the helmet during first five years of the helmet law in New Zealand was twenty-seven times greater than the estimated reduction of hospital cost from the injuries of bicycle-related accidents. Sieg (2016) estimated the benefit of a helmet law, mainly the benefit of increased security, was 0.7 of the cost of purchasing a helmet. Hendrie et al. (1999) estimated that the benefit of helmet law during the period of 1992-1998 was within a range of 30\%-109\% of the cost of the helmet law. Robinson (2007) supported these studies and claimed that the cost of helmet law would be much higher if some effects of wearing a helmet were measured such as discomfort of wearing helmet, pain from a wound to head. In reality, bicyclists invest in helmet based on their experiences and preferences rather than being rational. Young bicyclists would prefer to invest in Mountain Bike Adrenaline PC gameplay rather than on helmet. They perceive risks based on their experiences, character, and perception that are seen as non-rational and based among strategies (unclear text). From an individual perspective, it is complicated to justify "rationally" buying a helmet as they are based on previous incidents and findings from largescale data. For example, everybody knows that sugar increases the unhealthy level of blood fats, but the United States Department of Agriculture projected that the worldwide sugar consumption had reached a record of 173 million metric tons. Since there are fewer incidents of fatalities from bicycle-related accidents comparing to that of vehicle collisions, bicyclists cannot perceive the risks taken voluntarily. The relationship between the perceived risk and monetary benefit of not purchasing helmet is also linked to the strength of positive or negative affect associated with buying a helmet. University students were reluctant to buy the helmet not only based on what they thought about it but also on how they felt about it. Lupton and Tulloch (2002) stated that people perceived different types of risks based on how risk responses tend to be organized via heuristics. Lupton and Tulloch (2002) argued that people perceived a risk that is familiar or voluntary as less severe compared to risks that are rare and memorable. Minor injuries are prevalent and 
unremarkable for the bicyclists, and young bicyclists perceive risks less seriously and to some extent exciting. This study identifies that $70 \%, 14 \%, 13 \%$ and $3 \%$ respondents had minor, moderate, no injuries and significant injuries in bicycle-related accidents, respectively. Other factors also persuaded the young bicyclists to take voluntary risks such as self-confidence, increased stress tolerance, and to chase for the self-transcendent challenge and pleasurable excess.

Some respondents did not wear a helmet because of discomfort although they owned it. Lajunen and Räsänen (2004) observed a similar finding at two secondary schools in Northern Helsinki, Finland. Lajunen and Räsänen (2004) identified that $43.9 \%$ of respondents had bicycle helmets, but only $15.4 \%$ and $41.5 \%$ of them used helmet "often" and "never", respectively.

Young bicyclists were taking the risk not only by avoiding helmets but also by manoeuvring, over speeding and violating traffic signal. In Montreal, $45 \%$ bicycle-related injuries were for manoeuvring, over speeding and violating traffic signal during 2012-2014. This study observes that $50 \%$ respondents were bicycling at a speed of $20-28 \mathrm{~km} / \mathrm{h}$, while $34.85 \%$ and $15.15 \%$ respondents were bicycling at the speeds of $16-20 \mathrm{~km} / \mathrm{h}$ and higher than $28 \mathrm{~km} / \mathrm{h}$, respectively. Fyhri et al. (2012) estimated a strong correlation between accidents and speed cycling in Norway. Several studies in the United States revealed that high speed was the main reason for over occurrence of bicycle-related accidents among young male during the late afternoon and evening hours of summer months on urban and rural streets (Hunter et al. 1995; Wessels 1996). Like street skateboarding, over speeding is more pleasant and exciting to young bicyclists. These reflexive judgements attract and allure the young bicyclists to take risks. The attractiveness of risk and accomplishing the risk activities encourage the young bicyclists to take voluntary risks repeatedly.

Respondents were spontaneously taking risk bicycling in mixed traffic and avoiding the bicycle designated roads. Many respondents felt that bicycle-designated roads were overcrowded (29\%) and inconvenient (19\%). Some respondents $(24 \%)$ were optimizing their travel time by preferring shortest path rather than bicycling on designated roads. Interestingly, $14 \%$ respondents deliberately avoided designated roads to interact with the motorized traffic although $18 \%$ respondents are concerned for the collision with motor vehicles in the mixed traffic. The belief-underlying bicyclist's motive to ride with mixed urban traffic on busy urban roads instead of riding on designated roads is a contrary belief (Forward 2009). Respondents were less likely to believe that sharing the lanes of urban roads with motor vehicles (bicyclists were frequently biking on the left-lane of urban arterial roads that is the passing lane for high-speed motor vehicles) were risky and they would be involved in a collision with motor vehicles (Forward 2009). This argument is more evident knowing the contribution of bicycle-vehicle collisions to the bicycle-related injuries at Montreal that was 40\% during 2012-2014. Young bicyclists are taking voluntary risks not only by mixing with urban traffic but also by speeding up on the designated roads because of external pressure despite their own will, hard to avoid speeding and easy to speed up (Forward 2009). The first two factors of bicycle speeding are associated with a low control on behaviour, while the last one has higher control (Forward 2009).

Bicyclists are apathetic not only to wear a helmet but also to install the protective equipment on bicycles after the dark. Bicyclists require installing protective equipment on bicycles such as dynamiclights and reflective materials after the dark. Less than half of the respondents were using dynamic lights and wear bright cloths after the dark. The Vélo Quebec, a cycling advocacy group in Quebec province of Canada, claimed only a quarter of bicyclists on the Montreal roads were outfitted with the required reflectors and lights to make them visible to motorists and pedestrians in the dark. Only one in 10 bicyclists in Montreal has dynamic lighting as required by law. Respondents acknowledged that they had a false impression that streetlights provided sufficient brightness. However, just because a cyclist visualises does not mean he or she is visualised by others, mainly by those in motor vehicles. Quebec's Highway Safety Code requires all bicyclists to be equipped with front and rear lighting as well as reflectors during the night time. Bicyclist's perception of sufficient visibility under streetlights in dark increases the accidents. The Vélo Québec found the ratio of bicycle-related accidents and bicyclists in the dark is disproportionately high. There were 82 cases related to major bicycle-related injuries in Montreal in 2012, and out of that $60 \%$ cases occurred after the dark indicating the importance of protective equipment.

The above discussion reveals that young bicyclists took voluntary risks because they didn't perceive the risk or perceived the risk but did not take it seriously. To secure the safety of bicyclists, the individual behaviour of young bicyclists require to understand critically rather than introducing laws or expansion of bicycle- designated roads. Otherwise, the helmet law or investment on road infrastructure has no significant impact on the young bicyclists' attitude towards taking voluntary risks. The personal characteristics such as knowledge, attitudes, and beliefs that are improved by education, counselling, consideration of the positive and negative aspects of the behaviour, and exposure to others who do or do not wear helmets (Thompson et al. 2002). Young bicyclists also need to improve their ability to deal with the peer (e.g., friends) pressure for taking voluntary risks. Some other social and physical factors influence the young bicyclist's attitude such as social norms, economic incentives, social and economic rewards, law and enforcement of the law, and availability of helmets at stores (Thompson et al. 2002).

This study asked the university students about the practical ways to find out the factors that motivate the young bicyclists not to take voluntary risks. They supported for helmet law as the most efficient way followed by bicycle infrastructure and signs, educational program and increment of penalty fees (Fig. 2). From a behavioural perspective, 
helmet law associated with penalty fee significantly guides and balances the behaviour of bicyclists for and against helmets (Thompson et al. 2002). Helmet law also affects the social norms and increases the ability to resist the peer pressure against helmet use (Thompson et al. 2002). Female bicyclists are motivated to encourage their peer to avoid taking voluntary risks. Women believe more than men that traffic laws must always be obeyed regardless of their evaluation of the situation, and are more willing to accept the risk free situation (Yagil 1998).

Several studies found that educational programs were very useful to motivate the young bicyclists wearing a helmet and avoid taking voluntary risks (Ludwig et al. 2005; Mandic et al. 2016; Schieber et al. 1996). Mandic et al. (2016) studied 1453 adolescents from 12 secondary schools in Dunedin (New Zealand) and found that 38.5\% of adolescents perceived that cycle skills training makes them safer in traffic. Ludwig et al. (2005) distributed 259 free helmets under a bicycle helmet program "The Grateful Head" at a university campus in the Southeaster United States. Helmet recipients were committed to wearing the helmets with the "Grateful Head" sticker. Ludwig et al. (2005) also disseminated the information on the helmet use by the student agents and employees of bicycle shops. Ludwig et al. (2005) revealed that there was a significant increase in helmet use at the university over the course of study and in long-term. Schieber et al. (1996) identified that dissemination of helmet law was positively related to helmet use. Macknin and Mendendorp (1994) compared the helmet law with and without education program and found that the rate of helmet use was almost twice with education program scenario.

Information and knowledge along with enforcement of the law control the perception of young bicyclists towards taking voluntary risks because taking risks involve collecting and analysing knowledge and using it as part of a formal decision-making process. Several activities address the behavior of young bicyclists to avoid taking voluntary risks such as increase feelings of vulnerability and arranging public talks of the physical and psychological sufferings of victims of bicycle-related accidents. Young bicyclists also consider the helmet to reflect their values about life and health. Social media promotes the values that smart people wear a helmet. Future studies focus on the interactive and complex situations of mixed urban traffic that persuade the bicyclists to take voluntary risks.

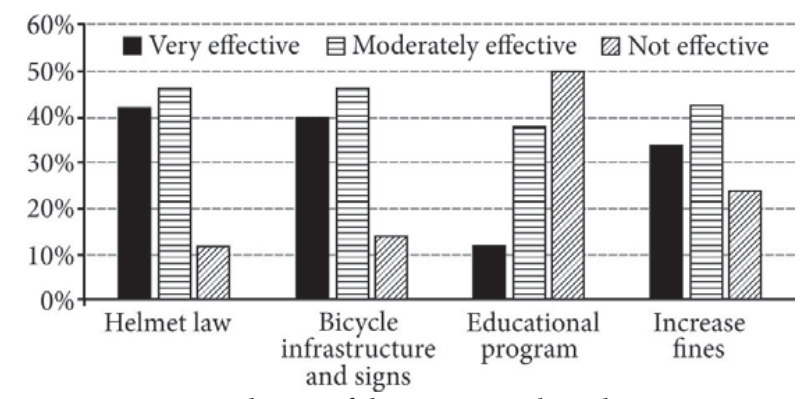

Fig. 2. Recommendation of the university bicyclists to improve the safety of bicyclists

\section{Conclusions}

1. This article analyses the behaviour of young bicyclists taking the voluntary risk. The university students in Montreal Island are considered as the case study since they are more risk takers and the bicycle is a favorite mode of transport among them.

2. More than half of respondents did not use helmets because of reluctant for short trips, uncomfortable and expenses. The decision not to wear helmet depended on the attitude, subjective norm and perceived behavioural control of the bicyclists.

3. University students were taking voluntary risks by over speeding, violating traffic signals and unwilling to wear helmet. They were also spontaneously taking risk bicycling in mixed traffic and avoiding the bicycledesignated roads arguing that the designated roads are overcrowded and inconvenient.

4. This study reveals that the bicyclists are reluctant to use running lights and reflective materials after the dark. Young bicyclists perceived the risk base on their experiences, character, and perception that are seen as non-rational and based on among strategies (unclear text). Since there are fewer incidents of fatalities from bicycle-related accidents comparing to that of vehicle collisions, they cannot perceive the severity of risks.

5. The personal behaviour of young bicyclists is critical along with laws or expansion of bicycle-designated roads to ensure the safety of bicyclists. The personal characteristics such as knowledge, attitudes, and beliefs are improved by education, counselling, consideration of the positive and negative aspects of the behaviour, and exposure to others who do or do not wear helmets.

6. Future studies focus on the interactive and complex situations of mixed urban traffic that persuade the bicyclists to take voluntary risks.

\section{References}

Bamberg, S.; Ajzen, I.; Schmidt, P. 2003. Choice of Travel Mode in the Theory of Planned Behavior: the Roles of Past Behavior, Habit, and Reasoned Action, Basic and Applied Social Psychology 25(3): 175-187.

https://doi.org/10.1207/S15324834BASP2503_01

Costa, C. 2014. Comparative Costs and Outcomes of Traumatic Brain Injury from Biking Accidents with or without Helmet Use: Ms. Thesis. Montreal, Canada: Physical Medicine and Rehabilitation Dept, McGill University Health Centre-Montreal General Hospital. 127 p. Available from Internet: https://papyrus. bib.umontreal.ca/xmlui/bitstream/handle/1866/11806/Costa_ Camille_2014_memoire.pdf?sequence $=2$ \&isAllowed $=y$

Forward, S. E. 2009. An Assessment of What Motivates Road Violations, Transportation Research Part F: Traffic Psychology and Behaviour 12(3): 225-234.

https://doi.org/10.1016/j.trf.2008.12.003

Fyhri, A.; Bjørnskau, T.; Backer-Grøndahl, A. 2012. Bicycle Helmets - a Case of Risk Compensation?, Transportation Research Part F: Traffic Psychology and Behaviour 15(5): 612-624. https://doi.org/10.1016/j.trf.2012.06.003 
Hagel, B. E.; Yanchar, N. L. 2013. Bicycle Helmet Use in Canada: the Need for Law to Reduce the Risk of Head Injury, Paediatrics \& Child Health 18(9): 475-480.

Hendrie, D.; Legge, M.; Rosman, D.; Kirov, C. 1999. An Economic Evaluation of the Mandatory Bicycle Helmet Legislation in Western Australia. In 1999 Insurance Commission of Western Australia Conference on Road Safety. Insurance Commission of Western Australia, Perth, 1 January 1999. 29 p.

Hunter, W. W.; Pein, W. E.; Stutts, J. C. 1995. Bicycle-Motor Vehicle Crash Types: the Early 1990s, Transportation Research Record 1502: 65-74.

Jewett, A.; Beck, L. F.; Taylor, C.; Baldwin, G. 2016. Bicycle Helmet Use among Persons 5 Years and Older in the United States, 2012, Journal of Safety Research 59: 1-7. https://doi.org/10.1016/j.jsr.2016.09.001

Ji, M.; Gilchick, R. A.; Bender, S. J. 2006. Trends in Helmet Use and Head Injuries in San Diego County: the Effect of Bicycle Helmet Law, Accident Analysis \& Prevention 38(1): 128-134. https://doi.org/10.1016/j.aap.2005.08.002

Kahneman, D.; Tversky, A. 1979. Prospect Theory: an Analysis of Decision under Risk, Econometrica 47(2): 263-292. https://doi.org/10.2307/1914185

Karkhaneh, M.; Kalenga, J. C.; Hagel, B. E.; Rowe, B. H. 2006. Effectiveness of Bicycle Helmet Law to Increase Helmet Use: a Systematic Review, Injury Prevention 12(2): 76-82. https://doi.org/10.1136/ip.2005.010942

Karkhaneh, M.; Rowe, B. H.; Saunders, L. D.; Voaklander, D. C.; Hagel, B. E. 2011. Bicycle Helmet Use Four Years After the Introduction of Helmet Law in Alberta, Canada,. Accident Analysis \& Prevention 43(3): 788-796.

https://doi.org/10.1016/j.aap.2010.10.026

Kett, P.; Rivara, F.; Gomez, A.; Kirk, A. P.; Yantsides, C. 2016. The Effect of an All-Ages Bicycle Helmet Law on Bicycle-Related Trauma, Journal of Community Health 41(6): 1160-1166. https://doi.org/10.1007/s10900-016-0197-3

Lajunen, T. 2016. Barriers and Facilitators of Bicycle Helmet Use among Children and Their Parents, Transportation Research Part F: Traffic Psychology and Behaviour 41(B): 294-301. https://doi.org/10.1016/j.trf.2015.03.005

Lajunen, T.; Räsänen, M. 2004. Can Social Psychological Models be Used to Promote Bicycle Helmet Use among Teenagers? A Comparison of the Health Belief Model, Theory of Planned Behavior and the Locus of Control, Journal of Safety Research 35(1): 115-123. https://doi.org/10.1016/j.jsr.2003.09.020

Ludwig, T. D.; Buchholz, C.; Clarke, S. W. 2005. Using Social Marketing to Increase the Use of Helmets among Bicyclists, Journal of American College Health 54(1): 51-58. https://doi.org/10.3200/JACH.54.1.51-58

Lupton, D.; Tulloch, J. 2002. Life Would be Pretty Dull without Risk': Voluntary Risk-Taking and Its Pleasures, Health, Risk \& Society 4(2): 113-124. https://doi.org/10.1080/13698570220137015

Macknin, M. L.; Mendendorp, S. V. 1994. Association between Bicycle Helmet Law, Bicycle Safety Education, and Use of Bicycle Helmets in Children, Archives of Pediatrics and Adolescent Medicine 148(3): 255-259. https://doi.org/10.1001/archpedi.1994.02170030025005

Macpherson, A. K.; Macarthur, C.; To, T. M.; Chipman, M. L.; Wright, J. G.; Parkin, P. C. 2006. Economic Disparity in Bicy- cle Helmet Use by Children Six Years after the Introduction of Law, Injury Prevention 12(4): 231-235.

https://doi.org/10.1136/ip.2005.011379

Macpherson, A.; Spinks, A. 2008. Bicycle Helmet Law for the Uptake of Helmet Use and Prevention of Head Injuries, Cochrane Database of Systematic Reviews 2008(3): CD005401. https://doi.org/10.1002/14651858.CD005401.pub3

McIntosh, A. S.; Lai, A.; Schilter, E. 2013. Bicycle Helmets: Head Impact Dynamics in Helmeted and Unhelmeted Oblique Impact Tests, Traffic Injury Prevention 14(5): 501-508. https://doi.org/10.1080/15389588.2012.727217

Mandic, S.; Flaherty, C.; Pocock, T.; Mintoft-Jones, A.; Frater, J.; Chillón, P.; Bengoechea, E. G. 2016. Attitudes Towards Cycle Skills Training in New Zealand Adolescents, Transportation Research Part F: Traffic Psychology and Behaviour 42(1): 217-226. https://doi.org/10.1016/j.trf.2016.08.002

Robinson, D. L. 2006. Do Enforced Bicycle Helmet Laws Improve Public Health? No Clear Evidence from Countries that Have Enforced the Wearing of Helmets, British Medical Journal 332(7543): 722-725. https://doi.org/10.1136/bmj.332.7543.722

Robinson, D. L. 2007. Bicycle Helmet Law: Can We Reach a Consensus? Accident Analysis \& Prevention 39(1): 86-93. https://doi.org/10.1016/j.aap.2006.06.007

Schieber, R. A.; Kresnow, M.; Sacks, J. J.; Pledger, E. E.; O’Neil, J. M.; Toomey, K. E. 1996. Effect of a State Law on Reported Bicycle Helmet Ownership and Use, Archives of Pediatrics and Adolescent Medicine 150(7): 707-712.

https://doi.org/10.1001/archpedi.1996.02170320053009

Sieg, G. 2016. Costs and Benefits of a Bicycle Helmet Law for Germany, Transportation 43(5): 935-949. https://doi.org/10.1007/s11116-015-9632-Z

Strauss, J.; Miranda-Moreno, L. F.; Morency, P. 2013. Cyclist Activity and Injury Risk Analysis at Signalized Intersections: aBayesian Modelling Approach, Accident Analysis \& Prevention 59: 9-17. https://doi.org/10.1016/j.aap.2013.04.037

Taylor, M.; Scuffham, P. 2002. New Zealand Bicycle Helmet LawDo the Costs Outweigh the Benefits? Injury Prevention 8(4): 317-320. https://doi.org/10.1136/ip.8.4.317

Thompson, N. J.; Sleet, D.; Sacks, J. J. 2002. Increasing the Use of Bicycle Helmets: Lessons from Behavior Science, Patient Education and Counseling 46(3): 191-197. https://doi.org/10.1016/S0738-3991(01)00212-9

Turner, S.; Wood, G.; Hughes, T.; Singh, R. 2011. Safety Performance Functions for Bicycle Crashes in New Zealand and Australia, Transportation Research Record 2236: 66-73. https://doi.org/10.3141/2236-08

Walker, I. 2007. Drivers Overtaking Bicyclists: Objective Data on the Effects of Riding Position, Helmet Use, Vehicle Type and Apparent Gender, Accident Analysis \& Prevention 39(2): 417-425. https://doi.org/10.1016/j.aap.2006.08.010

Wessels, R. L. 1996. Bicycle Collisions in Washington State: a SixYear Perspective, 1988-1993, Transportation Research Record 1538: 81-90. https://doi.org/10.3141/1538-11

Yagil, D. 1998. Gender and Age-Related Differences in Attitudes Toward Traffic Laws and Traffic Violations, Transportation Research Part F: Traffic Psychology and Behaviour 1(2): 123135. https://doi.org/10.1016/S1369-8478(98)00010-2

Received 22 March 2017; accepted 08 September 2017 